\title{
Management of a Case of Megaloblastic Anemia with Pancytopenia in Late Pregnancy: A Case Review
}

\author{
Archana M Pati
}

\begin{abstract}
Aims and objectives: Early diagnosis and management of a case of $\mathrm{B}^{12}$ and folic acid deficiency, as there is no gold standard protocol for diagnosis of this type of anemia.
\end{abstract}

Case report: A 24 years G2P1L1A0 with 32 weeks gestation presented with: $\mathrm{Hb}: 3 \mathrm{~g} \%$, red blood cells (RBCs: 1700 cells/ $\mathrm{mm}^{3}$, white blood cells (WBCs): 2700 cells $/ \mathrm{mm}^{3}$, platelets: 80000 cells $/ \mathrm{mm}^{3}$.

Ultrasound is suggestive of single live intrauterine pregnancy of 32.4 weeks, with cephalic presentation with symmetrical intrauterine growth restriction, amniotic fluid index (AFI): 7-8 cm. Obstetric Doppler suggestive of increased SD ratio in umbilical artery, reduced periodontal index $(\mathrm{PI})$ in the right uterine artery.

Patient treated with 3 units of packed cell colume (PCV) with 3 doses of intravenous $B^{12}$ and vitamin $C$ injections followed by oral iron, oral $\mathrm{B}^{12}$, and folic acid.

Patient advised follow-up after 15 days.

Reports after 15 days:

Hb: 8.6 g\%, RBCs: $3.07 \times 10_{12} / L$, WBCs: $10.2 \times 10_{g} / L$, Pletlets: $33.2 \times 10 \mathrm{~g} / \mathrm{L}$

Ultrasound is suggestive of single live intrauterine pregnancy of 33.3 weeks gestation with cephalic presentation, AFI: $8-9 \mathrm{~cm}$.

Obstetric Doppler: No significant abnormality in obstetric Doppler indices in the present scan.

Conclusion: Early intervention and diagnosis of megaloblastic anemia in late pregnancy reduce significant maternal and fetal morbidity and mortality.

Keywords: Folic acid, Megaloblastic anemia, Morbidity, Mortality, Pancytopenia, Vitamin $\mathrm{B}^{12}$.

How to cite this article: Patil AM. Management of a Case of Megaloblastic Anemia with Pancytopenia in Late Pregnancy: A Case Review. World J Anemia 2018;2(2):61-65.

Source of support: Nil

Conflict of interest: None

\section{Fellow}

Department of Fetal Medicine, Fernandez Hospital Foundation, Hyderabad, Telangana, India

Corresponding Author: Archana M Patil, Fellow, Department of Fetal Medicine, Fernandez Hospital Foundation, Hyderabad, Telangana, India, e-mail: archana.prital@gmail. com

\section{INTRODUCTION}

Folic acid is needed in higher doses ${ }^{1}$ in pregnancy because of the increased cell replication taking place in fetus, uterus and bone marrow. World Health Organization (WHO) recommends $800 \mu \mathrm{g}$ folic acid per day. Preexisting deficiency is common in developing countries. It is mainly due to inadequate diet, intestinal malabsorption syndrome.

Vit $\mathrm{B}^{12}$ is required for proper red blood cell formation, neurological functions and DNA synthesis. Recommended daily allowances (RDA) for vitamin $B^{12}$ in pregnancy is $2.6 \mu \mathrm{g}$ per day. ${ }^{2}$ The main causes of vitamin $B^{12}$ deficiency include vitamin $B^{12}$ malabsorption from food, pernicious anemia, post-surgical cause, and dietary deficiency.

\section{CASE REPORT}

G2P1L1AO aging 24 years came with 8 months amenorrhea with a history of decreased appetite for 3 months,

Generalized weakness for 4 days, breathlessness for 4 days, swelling all over body for 4 days.

The patient had a report of $\mathrm{Hb} 6 \mathrm{~g} \%$ at 20 weeks of gestational age for that patient had taken the treatment in the form of injectable iron only and when it dropped to $3 \mathrm{~g} \%$, the patient was referred to tertiary referral center by the treating hospital.

I advised the complete anemia profile, ANC profile and obstetric ultrasound.

- The reports were: $\mathrm{Hb}: 3 \mathrm{~g} \%, \mathrm{PCV}: 9.1 \mathrm{vol} \%$, RBCs: 1,070 cells $/ \mathrm{mm}^{3}$, WBCs: 2,700 cells $/ \mathrm{mm}^{3}$, platelets: 80,000 cells $/ \mathrm{mm}^{3}$ (Graph 1).

- PS for an expert opinion: RBCs show severe anisopoikilocytosis, macrocytes ++ , microcytes ++ , tear drop cells +, fragmented RBCs +, few polychromatic RBCs seen, TLC reduced, platelets decreased on smear, no hemoparasite seen (Fig. 1).

- KFTs: Blood urea-29 mg/dL, serum creatine-06 mg/ dL.

- Fasting blood sugar: $100 \mathrm{mg} / \mathrm{dL}$, post lunch blood sugar 2 hours: $121 \mathrm{mg} / \mathrm{dL}$.

- LFTs: Serum bilirubin total-1.4 mg/dL, direct: $0.5 \mathrm{mg} /$ $\mathrm{dL}$, indirect: $0.9 \mathrm{mg} / \mathrm{dL}$.

- Serum alkaline phosphatase: 100.4 U/L, SGPT: 33 units/L, SGOT: 45 units/L.

- Sr. proteins: $6.1 \mathrm{~g} / \mathrm{dL}$, Sr. albumin-3 g/dL, Sr. globulin-3.1 g/dL, A/G ratio-0.96. 


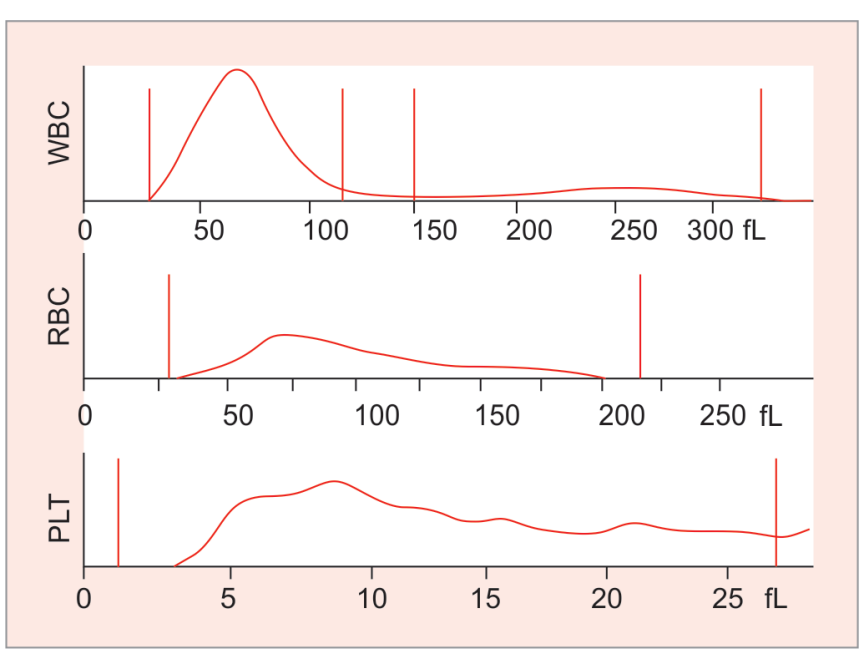

Graph 1: Automated histogram showing pancytopenia

- Sr. Vitamin $B^{12}: 111.4 \mathrm{pg} / \mathrm{mL}$

- Folic acid: $1 \mathrm{ng} / \mathrm{mL}$

- Sr. Ferritin: $413.6 \mathrm{ng} / \mathrm{mL}$

- Urine: Albumin-trace, pus cells-5-6/HPF, red cellsnil, epithelial cells-16-18/HPF

\section{Obstetric Ultrasound}

Thirty-two weeks, 4 days single live intrauterine pregnancy with cephalic presentation, $\mathrm{BPD} / \mathrm{HC}$ and $\mathrm{AC}$ are less than 3 percentile suggestive of symmetrical intrauterine growth restriction, placenta found posterior, AFI $7-8 \mathrm{~cm}$. Movements and cardiac activity regular.

\section{Obstetric Doppler}

There was a slightly raised S/D ratio in the midportion of the umbilical artery. Right uterine artery showed reduced PI. The flow pattern in rest vessels was normal.

\section{Ultrasound of Abdomen}

Within normal limits, patient admitted in intensive care unit for 2 days and treated with 3 units of PCV and parenteral administration of 3 doses of vitamin $\mathrm{B}^{12}$ and vitamin $\mathrm{C}$ as per hematologist's recommendation.

On D3 patient discharged with a platelet count of 41,000 cells $/ \mathrm{mm}^{3}$, advised follow-up after 15 days for a complete blood count.

After 15 days reports were:

- Hb: 8.6 g\%, PCV: 28.3 g\%, RBCs: 3,07000 cells $/ \mathrm{mm}^{3}$, WBCs: 10,200 cells $/ \mathrm{mm}^{3}$,

- Platelets: 3,32000 cells $/ \mathrm{mm}^{3}$ (Graph 2).

\section{Obstetric Ultrasound}

Single live intrauterine pregnancy of 33 weeks 3 days with cephalic presentation with a single loop of cord around the neck.

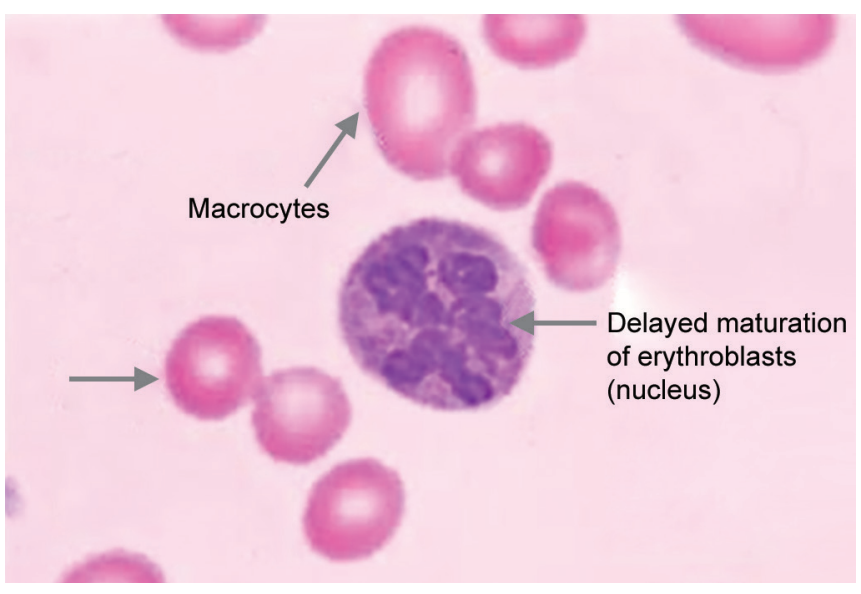

Fig. 1: Erythrogram showing blood picture of megaloblastic anemia

\section{Obstetric Color Doppler}

No significant abnormality in obstetric Doppler indices at present study.

\section{Treatment Modalities}

\section{Indications for Blood Transfusion}

- Severe anemia in later months of pregnancy.

- Refractory anemia.

- Quality and quantity: Fresh only packed cells 80-100 $\mathrm{mL}$ at a time.

\section{Advantages of PCV}

- Increased oxygen carrying capacity of the blood

- $\mathrm{Hb}$ may be utilized for the formation of new blood cells

- Stimulate erythropoiesis

- Improvement expected after 3 days.

\section{Treatment of vit $\mathbf{B}^{12}$ Deficiency}

- Hydroxycobalamine $e^{4} 1000 \mu \mathrm{g}$ can be given IM to a total of $5.6 \mathrm{mg}$ over the course of 3 weeks. $1000 \mathrm{\mu g}$ is then necessary every 3 months for the rest of life.

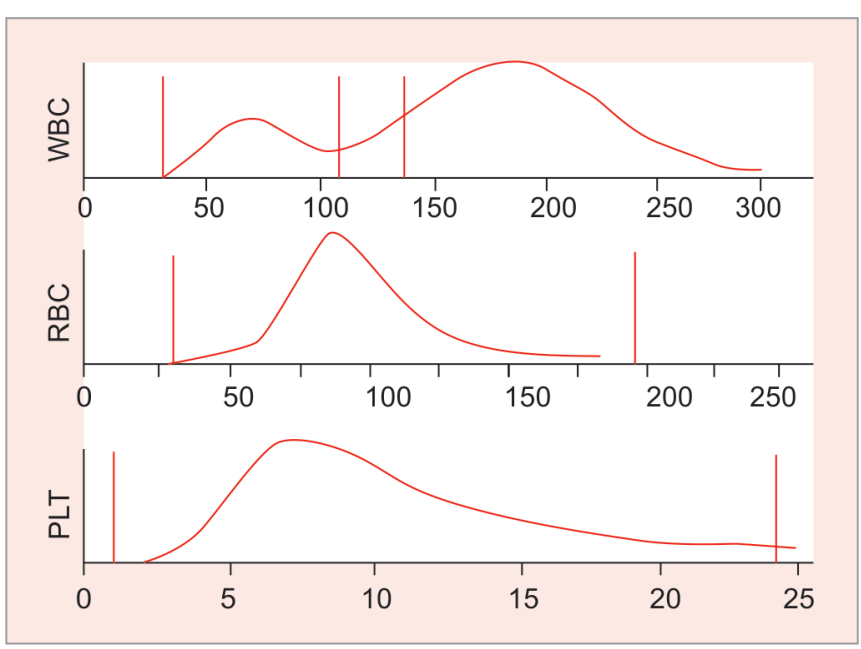

Graph 2: Automated histogram showing normal cell count after treatment 
It is now recommended that oral vitamin $\mathrm{B}^{12} 2 \mathrm{mg} /$ day is given as $1-2 \%$ of an oral dose is absorbed by diffusion, therefore, does not require intrinsic factor.

- A $2000 \mu \mathrm{g}$ of oral vitamin $B^{12}$ daily, followed by a decreased daily dose of $1000 \mu \mathrm{g}$ then $1000 \mu \mathrm{g}$ weekly and finally monthly might be as effective as intramuscular administration.

\section{Treatment of Folate Deficiency}

Folate deficiency ${ }^{4}$ can be corrected by giving $5 \mathrm{mg}$ of folic acid daily, treatment ${ }^{4}$ should be given for about 4 months to replace body stores, any ${ }^{4}$ underlying cause should be treated, prophylactic folic acid (400 $\mu \mathrm{g}$ daily) is recommended to reduce neural tube defects, women ${ }^{4}$ who have had a child with a neural tube defect should take $5 \mathrm{mg}$ folic acid before and during a subsequent pregnancy.

\section{CLINICAL SIGNIFICANCE}

\section{Megaloblastic Anemia}

Megaloblastic anemia ${ }^{5}$ is anemia that results from inhibition of DNA synthesis during red blood cell production. When DNA synthesis is impaired, the cell cycle cannot progress from the $\mathrm{G} 2$ growth stage to the mitosis (M) stage. ${ }^{6}$ Megaloblastic anemia is one of the acquired nutritional anemias that may complicate pregnancy. It is most often secondary to folic acid deficiency because folate requirements are increased .

\section{Folate Deficiency}

It mimics low levels ${ }^{7}$ of folic acid and derivatives in the body. Also known as vitamin $\mathrm{B}^{9}$, folate is involved in adenosine, guanine, and thymidine synthesis. Anemia is late finding in folate deficiency. ${ }^{7}$ It is characterized by the appearance of large-sized, abnormal red blood cells (megaloblasts), which form when there are inadequate stores of folic acid within the body.

A deficiency ${ }^{7}$ of folate can occur when the body's need for folate is increased when dietary intake or absorption of folate is inadequate, or when the body excretes more folate than usual. Medications like anticonvulsants, metformin, methotrexate, sulfasalazine, triamterene, ${ }^{8}$ birth control pills that interfere with the body's ability to use folate may also increase the need for this vitamin. Research indicataes that exposure to ultraviolet light, including the use of tanning beds, can lead to folate deficiency. ${ }^{9}$ The deficiency is more common in pregnant women, infants, children, and adolescents.

A defect ${ }^{10}$ in homocysteine methyltransferase or a deficiency of $\mathrm{B}^{12}$ may lead to a so-called "methyl trap "tetrahydrofolate (THF), in which THF is converted to a reservoir of methyl-THF which thereafter has no way of being metabolized, and serves as a sink of THF that causes a subsequent deficiency of folate. Thus, a deficiency in vitamin $\mathrm{B}^{12}$ can generate a large pool of methyl-THF that is unable to undergo reactions and will mimic folate deficiency.

Folate $^{7}$ deficiency during gestation or infancy due to development by the fetus or infant of autoantibodies to the folate receptor might result in various developmental disorders including autism spectrum disorders. Studies suggest that insufficient folate and vitamin $\mathrm{B}^{12}$ status may contribute to major depressive disorder and that supplementation might be useful in this condition. The role of vitamin $\mathrm{B}^{12}$ and folate in depression is due to their role in transmethylation reactions, which are crucial for the formation of neurotransmitters (e.g., serotonin, epinephrine, purines, nicotinamides, phospholipids) The proposed mechanism, is that low levels of folate or vitamin $B^{12}$ can disrupt transmethylation reaction, leading to an accumulation of homocysteine (hyperhomocysteinemia) and to impaired metabolism of neurotransmitters (especially the hydroxylation of dopamine and serotonin from tyrosine and tryptophan) phospholipids, myelin, and receptors. High homocysteine levels in the blood can lead to vascular injuries by oxidative mechanisms which can contribute to cerebral dysfunction. All of these can lead to the development of various disorders, including depression.

Vitamin $B^{12}$ exists in several forms and contains the mineral cobalt, so compounds with vitamin $\mathrm{B}^{12}$ activity are collectively called "cobalamins". Methylcobalamin is the forms of vitamin $B^{12}$ that are active in human metabolism. ${ }^{11}$ Vitamin $B^{12}$ functions as a cofactor for methionine synthase and L-methylmalonyl-CoA mutase. Methionine synthase catalyzes the conversion of homocysteine to methionine. Methionine is required for the formation of S-adenosylmethionine, a universal methyl donor for almost 100 different substrates, including DNA, RNA, hormones, proteins, and lipids. L-methylmalonyl-CoA mutase converts L-methylmalonyl-CoA to succinyl-CoA in the degradation of propionate, an essential biochemical reaction in fat and protein metabolism. Succinyl-CoA is also required for hemoglobin synthesis.

Vitamin $\mathrm{B}^{12}$ deficiency is an independent risk factor for fetal neural tube defects. The underlying mechanisms involve the homocysteine ${ }^{12}$ pathway by elevation in plasma homocysteine.

\section{Vitamin $B^{12}$ Deficiency}

Pathological ${ }^{13}$ changes that occur due to $\mathrm{B}^{12}$ deficiency are demyelination, axonal degeneration, neuronal death elevation in homocysteine, reduced tetrafolate as well 
as the secondary elevation of guanidinoacetate may be involved in the pathogenesis of encephalopathy. ${ }^{12}$ This deficiency has also been associated with recurrent fetal loss and neonatal death. Bennet found that severe deficiency caused a high incidence of recurrent fetal loss. The cause of this recurrent fetal loss is two-fold. It is due to damage to decidua and chorial vessels leading to abnormal placentation and secondary because of direct embryotoxicity from hyperhomocysteinemia, can cause anencephaly, this may be due to the vitamin $\mathrm{B}^{12}$ is involved in the metabolism of neural tissue.

\section{Pancytopenia}

It is the simultaneous presence of anemia, leukopenia, and thrombocytopenia. ${ }^{13}$ The underlying mechanism is decreased in hemopoietic cells production, marrow replacement by abnormal cells, suppression of marrow growth and differentiation, ineffective hematopoiesis with cell death, defective cell formation which are removed from circulation, antibody-mediated sequestration or destruction of cells and trapping of cells in a hypertrophied and overactive reticuloendothelial system.

Megaloblastic anemia ${ }^{13}$ as a cause of pancytopenia falls in the wide range of results reported in local studies vary from 38 to $72 \%$.

\section{Folic Acid and Vitamin $\mathbf{B}^{12}$}

Large amounts of folic ${ }^{2}$ acid can mask the damaging effects of vitamin $\mathrm{B}^{12}$ deficiency by correcting the megaloblastic anemia caused by vitamin $B^{12}$ deficiency without correcting the neurological damage that also occurs. Preliminary evidence suggests that high serum folate levels might not only mask vitamin $\mathrm{B}^{12}$ deficiency, but could also exacerbate the anemia and worsen the cognitive symptoms associated with vitamin $\mathrm{B}^{12}$ deficiency. Permanent nerve damage can occur if vitamin $\mathrm{B}^{12}$ deficiency is not treated. For these reasons, folic acid intake from fortified food and supplements should not exceed 1,000 $\mu \mathrm{g}$ daily in healthy adults.

\section{Complications of Severe Anemia}

\section{During Pregnancy}

- Preeclampsia

- Intercurrent ${ }^{14}$ infection

- Heart failure

- Preterm labor.

\section{During Labor}

- Uterine inertia

- Postpartum hemorrhage
- Cardiac failure

- Shock.

\section{During Puerperium}

- Subinvolution

- Failing lactation

- Pulmonary embolism.

\section{Risk Periods During Pregnancy with Severe Anemia}

- At about 30-32 ${ }^{14}$ weeks of pregnancy.

- During labor.

- Immediate following delivery.

- Any time in puerperium especially 7 to 10 days following delivery.

\section{Differential Diagnosis}

Many rare cases of megaloblastic anemia (unrelated to vitamin deficiency) have been identified including rare enzyme deficiencies known as inborn errors of metabolism and primary bone disorder including myelodysplastic syndromes ${ }^{15}$ and acute myeloid leukemia.

\section{CONCLUSION}

Early intervention and diagnosis of megaloblastic anemia in late pregnancy reduce significant maternal and fetal morbidity and mortality.

\section{REFERENCES}

1. Johnston,Tracey." Anaemia ", Obstetrics and Gynaecology An evidence - based text for MRCOG (2E), 2010.

2. www.b12 vitamin.co.za.vitamin b12.Home page (Internet)

3. Garcia SS, Atkins JT, Falchook GS, Tsimberidou AM, Hong DS, Trivedi MV, et al. Transient severe hyperbilirubinemia after hepatic arterial infusion of oxaliplatin in patients with liver metastases. Cancer chemotherapy and pharmacology. 2013 Dec 1;72(6):1265-1271.

4. Chandra J. Megaloblastic Anaemia. MedIND. medind.nic.in/ icb/t10/i7/icbt10i7p79 5.pdf.2010 (Internet)

5. Megaloblastic Anaemia. Malaga Health Foundation http:// www.malagahealth.com/condition/megaloblastic-anaemia (Internet).

6. Davenport DF, Blackford J, Bishop MR, Sommardahl CS, Martin EJ. Equine therapeutic nutrition i \& ii, nutritional supplement ingredients, the good, the bad and the useless. Proceedings WWVC. 2002:707-720.

7. en.wikipedia.org .Megaloblastic anaemia.https:// en.wikipedia.org/wiki/Megaloblastic_anemia.Edit sept 2018 (Internet)

8. PCOS using hydroxycut Hydroxycut weight Loss Pills - July 27, 2017

9. Health. Nutritional Imbalance. Vitamin Deficiencies \& Excesses. http://body-disease.com/category/health/

10. Megaloblastic Anaemia - Vit B12 deficiency Slide Share https:/ /lessonnote.net/wp-https:/ / www.slideshare.net/ 
drshahinhameed/megaloblastic-anemia-vit-b12-deficiency.

11. Pernicious Anaemia. Article 164() tiss-net mba gk compendiumlessonnote.net (content/uploads/2019/02/T\%C4\%B1ssNet-Mba-Gk- Compendium-2016-17.pdf) http://weiodat. blogspot.com/2015/05/polycystic-ovaries).

12. Akhtar M, Hassan I. Severe anaemia during late pregnancy. Case reports in obstetrics and gynecology. 2012;2012.

13. Makheja KD, Maheshwari BK, Arain S, Kumar S, Kumari S. The common causes leading to pancytopenia in patients pre- senting to tertiary care hospital. Pakistan journal of medical sciences. 2013 Sep;29(5):1108-1111.

14. Vitamin B12-NIH. https://ods.od.nih.gov/factsheets/Vitamin B12-HealthProfessional.Nov 292018 (Internet). 15. Ph+ Chronic Myeloid Leukemia(CML) Symptoms - Tasigna https:// www.us.tasigna.com/about-the-disease/signs--symptoms/.

15. Carmen Emanuela ,"Chapter 6 New Insights into the Diagnosis and Management of Pregnancy - Related Diabetes Insipidus"', In Tech, 2011. 